\title{
Amperometric Detection of Gallic Acid Based on Electrochemically Activated Screen Printed Carbon Electrode
}

\author{
N. Raja ${ }^{1}$, T. Kokulnathan ${ }^{1}$, Shen-Ming Chen ${ }^{1 *}$, Wei-Cheng Liao ${ }^{1}$, T. Sakthi Priya ${ }^{2}$ \\ ${ }^{1}$ Electroanalysis and Bioelectrochemistry Lab, Department of Chemical Engineering and \\ Biotechnology, National Taipei University of Technology, No.1, Section 3, Chung-Hsiao East Road, \\ Taipei 106, Taiwan (R.O.C). \\ ${ }^{2}$ Department of chemistry, Vellalar College for Women, Erode 638 012, Tamil Nadu, India. \\ *E-mail: smchen78@ms15.hinet.net (S-M Chen)
}

doi: $10.20964 / 2017.06 .22$

Received: 10 February 2017 / Accepted: 17 March 2017 / Published: 12 May 2017

\begin{abstract}
A simple electrochemical sensor based on activated screen printed carbon electrode (ASPCE) was successfully fabricated for the selective and sensitive amperometric determination of gallic acid (GA). The activated screen printed carbon electrode (ASPCE) was fabricated by simple electrochemical technique and it was characterized by using scanning electron microscopy (SEM), Raman spectroscopy and electron impedance spectroscopy (EIS). The electrochemical properties of the electrodes were investigated by the cyclic voltammetry and amperometric method. Interestingly, ASPCE exhibited an excellent electrocatalytic activity in terms of decrease the potential and increase the anodic peak current for the detection of GA when compared to bare SPCE. The ASPCE was successfully determined the GA and it showed good wide linear response range from 0.01 to 1799.6 $\mu \mathrm{M}$ and the lowest detection limit (LOD) of $0.031 \mu \mathrm{M}$. Moreover, the fabricated sensor electrode was manifested a good selectivity, stability, repeatability and reprodubility. The sensor was applied to the determination of GA in real samples, where it shows good recovery and accuracy. To the best of our knowledge, this electrode is cost effective and excellent performance towards the detection of GA when compared with previously reported other chemically modified electrodes.
\end{abstract}

Keywords: Gallic acid, Amperometric technique, Cyclic voltammetry, Activated screen printed carbon electrode.

\section{$\underline{\text { FULL TEXT }}$}

(C) 2017 The Authors. Published by ESG (www.electrochemsci.org). This article is an open access article distributed under the terms and conditions of the Creative Commons Attribution license (http://creativecommons.org/licenses/by/4.0/). 